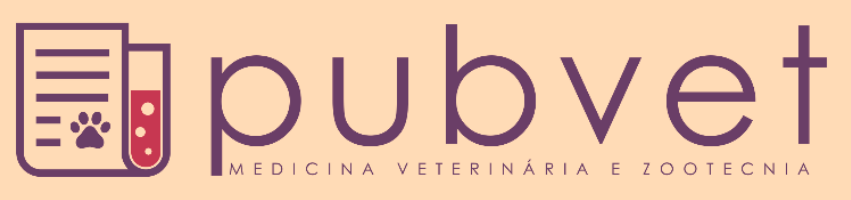

https://doi.org/10.31533/pubvet.v13n1a255.1-1 1

\title{
Bem-estar na bovinocultura leiteira: Revisão
}

\author{
Dariane Fontes da Silva ${ }^{1}$, Alberto Jefferson da Silva Macêdo ${ }^{2 *}$, Vinicius de França Carvalho \\ Fonsêca $^{3}$, Edilson Paes Saraiva ${ }^{4}$ \\ ${ }^{I}$ Zootecnista, Bananeiras-PB, Brasil.E-mail: dari.bans@hotmail.com \\ ${ }^{2}$ Discente do curso de Doutorado em Zootecnia, Universidade Federal de Viçosa. Viçosa-MG, Brasil ${ }^{3}$ Discente do curso de \\ Pós-Doutorado em Zootecnia, Universidade Estadual Paulista Júlio de Mesquita Filho. Jaboticabal-SP, Brasil. \\ ${ }^{4}$ Professor da Universidade Federal da Paraíba, Departamento de Zootecnia. Areia-PB, Brasil. \\ *Autor para correspondência.E-mail: macedoajs@gmail.com
}

Resumo. O sistema de criação exerce grande influência na atividade leiteira e o emprego do bem-estar animal na produção de leite proporciona resultados positivos na produtividade. O conhecimento dos efeitos sobre o bem-estar provindo de doenças, traumas, fome, estímulos benéficos, interações sociais, condições de alojamento, manejo inadequado, transporte, mutilações, tratamento veterinário ou alterações genéticas é essencial. Diversos são os tipos de sistema de criação para bezerros, mas, devem-se considerar os principais fatores de riscos (temperatura, radiação solar, umidade, ventilação e superlotação das instalações). As instalações precisam proteger os bezerros contra os ventos fortes e alta umidade deve garantir conforto permitindo que o animal expresse todo seu potencial genético. O período neonatal (até 28 dias de idade) representa $75 \%$ das perdas no primeiro ano de vida, diante disso, para evitar perdas é imprescindível cuidados especiais com a saúde e com o desenvolvimento das futuras matrizes. Objetiva-se nesta revisão descrever a importância do conhecimento sobre bem-estar animal. Relatar comportamentos, pois é através dos padrões comportamentais que os animais tentam adaptar-se à influência dos agentes estressores. Apresentar os sistemas de aleitamento e os diferentes sistemas de criação para bezerros.

Palavras chave: comportamento, estresse, manejo de bezerros

\section{Animal welfare in dairy cattle: Review}

Abstract. The breeding system exerts great influence on dairy activity and the use of animal welfare in milk production provides positive results in productivity. Knowledge of the effects on well-being from diseases, trauma, hunger, beneficial stimuli, social interactions, housing conditions, inadequate management, transportation, mutilation, veterinary treatment or genetic alterations is essential. There are several types of breeding system for calves, but the main risk factors (temperature, solar radiation, humidity, ventilation and overcrowding of the facilities) should be considered. The facilities need to protect the calves against high winds and high humidity; they should ensure comfort allowing the animal to express its full genetic potential. The neonatal period (up to 28 days of age) accounts for $75 \%$ of the losses in the first year of life. In order to avoid losses, it is essential to pay special attention to the health and development of future mothers. The objective of this review is to describe the importance of knowledge about animal welfare. Report behaviors, because it is through behavioral patterns that animals try to adapt to the influence of stressors. To present the systems of suckling and the different breeding systems for calves.

Keywords: behavior, stress, calf management 


\section{Bienestar en la ganadería lechera: Revisión}

Resumen. El sistema de cría ejerce una gran influencia en la actividad lechera y el empleo del bienestar animal en la producción de leche proporciona resultados positivos en la productividad. El conocimiento de los efectos sobre el bienestar proveniente de enfermedades, traumas, hambre, estímulos benéficos, interacciones sociales, condiciones de alojamiento, manejo inadecuado, transporte, mutilaciones, tratamiento veterinario o alteraciones genéticas es esencial. Diversos son los tipos de sistema de cría para terneros, pero se deben considerar los principales factores de riesgo (temperatura, radiación solar, humedad, ventilación y hacinamiento de las instalaciones). Las instalaciones necesitan proteger a los becerros contra los vientos fuertes y alta humedad, deben garantizar comodidad permitiendo que el animal exprese todo su potencial genético. El período neonatal (hasta 28 días de edad) representa el $75 \%$ de las pérdidas en el primer año de vida, frente a ello, para evitar pérdidas es imprescindible cuidados especiales con la salud y con el desarrollo de las futuras matrices. Se pretende en esta revisión describir la importancia del conocimiento sobre bienestar animal. Informar de comportamientos, pues es a través de los patrones comportamentales que los animales intentan adaptarse a la influencia de los agentes estresores. Presentar los sistemas de lactancia y los diferentes sistemas de cría para terneros.

Palabras clave: comportamiento, estrés, manejo de terneros

\section{Introdução}

O desconhecimento da senciência animal, tornou a produção animal opressora por alguns anos. Em que, modificar geneticamente o animal estava ligado a um objetivo específico, como exemplo: obter melhores índices produtivos, sem haver preocupações com o bem-estar dos animais. Todavia, não se podem trazer para o século XXI esses comportamentos, mas também dispensar totalmente, se expressa em atrasos nos processos de seleção e melhoramento genético. É preciso equilibrar as variáveis relacionadas com o aprimoramento ético (Martins \& Pieruzzi, 2011). A população tem se preocupado a cada dia com a saúde e o bem-estar animal, reflexo de um maior conhecimento acerca da temática.

O emprego do bem-estar animal na produção leiteira aliado aos fatores de produção proporcionam melhores desempenhos. Um sistema de seleção eficiente e uso de raças adaptadas ao meio ambiente, são fatores importantes que podem levar a um bom desempenho não só econômico, mas também na relação humano-animal (Martins \& Pieruzzi, 2011). É imprescindível que o sistema de criação adotado, seja de baixo custo e rentável, que proporcionem melhores condições naturais, conforto, facilidade de manejo, movimentação e permita que o animal expresse todo seu potencial genético (Oliveira et al., 2007).

Animais de produção criados em sistemas confinados podem ser frustrados e estressados, ocasionando um bem-estar pobre (Broom \& Molento, 2004; Pedreira \& Primavesi, 2011). Tendo em vista que o estado o qual o animal se encontra interfere diretamente na qualidade de vida, comprometendo o seu bem-estar e pondo em risco a qualidade dos produtos de origem animal como: leite, carne, ovo.

Objetiva-se nesta revisão descrever a importância do conhecimento sobre bem-estar animal. Relatar comportamentos, pois é através dos padrões comportamentais que os animais tentam adaptar-se à influência dos agentes estressores. Apresentar os sistemas os sistemas de criação para bezerros.

\section{Bem-estar animal}

É de fundamental importância o conhecimento dos efeitos sobre o bem-estar provindo de doenças, traumas, fome, estímulos benéficos, interações sociais, condições de alojamento, manejo inadequado, transporte, mutilações, tratamento veterinário ou alterações genéticas. Alguns indivíduos conseguem lançar mão de diversos mecanismos de adaptação os quais pode envolver atividades, em parte do cérebro, respostas endócrinas, imunológicas e comportamentais. Mesmo assim, se diante dos desafios o indivíduo não conseguir enfrentá-lo com êxito, provavelmente demonstrará sinais de falência adaptativa, 
que consequentemente resultará em falência no seu desenvolvimento, em sua reprodução ou até morte (Broom, 1986; Broom \& Molento, 2004). Para definir o bem-estar animal (BEA) é fundamental uma estreita relação com as necessidades, adaptações, controles, liberdades, sentimentos, sofrimento, dor, ansiedade, medo, estresse e saúde. O bem-estar não pode ser compreendido somente como um estado absoluto, presente ou não, ou relacionado somente a algo bom. O BEA apresenta-se como adequado ou alto, bem como pobre ou baixo e "bem-estar bom" e "bem-estar ruim" expressões válidas cientificamente (Broom \& Molento, 2004).

Segundo Broom \& Molento (2004) Organização Mundial de Saúde Animal (Gibbs, 2014) um animal encontra-se em bom estado de bem-estar, quando está saudável, seguro e em conforto, bem nutrido e capaz de expressar comportamentos naturais. Em contrapartida o estado desconfortável (dor, medo e angústia) representam um bem-estar ruim. A mensuração fisiológica possibilita a identificação de alguns sinais de bem-estar precário, a exemplo, o aumento na frequência cardíaca, respostas imunológicas reduzidas após um desafio ou atividade adrenal após desafio, aumentando a secreção do hormônio adrenocorticotrófico (ACTH).

Os estudos etológicos servem para interpretar comportamentos e compreender as necessidades biológicas das espécies. A avaliação do BEA pode ser realizada de forma objetiva e independente de considerações éticas sobre os sistemas, práticas ou condições dos indivíduos. Existem algumas variáveis (taxa de natalidade, sucesso reprodutivo, indicadores comportamentais, nível de incidência de doenças, gravidade de injúrias, extensão da atividade adrenal) que podem ajudar a inferir a respeito do bem-estar animal. Mensurar o comportamento tem valor semelhante a avaliação de bem-estar. Quando um animal evita ou se esquiva de determinado objeto ou evento, proporciona informações sobre seus sentimentos, que consequentemente interferem no seu bem-estar. Quanto mais forte a reação, mais pobre o seu bemestar (Broom, 1986; Broom \& Molento, 2004).

Os animais possuem diferentes necessidades, algumas em particular, tais como água ou calor, outras associadas à senciência chamadas de experiências subjetivas. Outras necessidades são obtidas pela observação de anormalidades comportamentais ou fisiológicas, indicando que suas necessidades não foram satisfeitas. Os sistemas de controle nos animais têm evoluído tanto, que o objetivo específico, tornou-se mais importante. E, a necessidade de realizar um determinado comportamento é bloqueada impossibilitando sua execução (Broom, 1986; Broom \& Molento, 2004).

Animais de produção intensivamente confinados podem ser frustrados e estressados. Os alojamentos individuais impossibilitam a expressão dos comportamentos naturais de bezerros, com exceção de deitar-se, levantar-se e dar poucos passos (Pedreira \& Primavesi, 2011). Instalações que restringem de forma severa a possibilidade de locomoção dentro da mesma levam o animal apresentar bem-estar pobre. Animais criados em sistemas confinados, tem seu bem-estar mais pobre. Bezerros quando criados em baias ou gaiolas pequenas, ou gaiolas metabólicas, tentam limpar-se exaustivamente, porém esse comportamento torna-se impossível devido à restrição de espaço no lugar os quais foram inseridos (Broom \& Molento, 2004). De acordo com Bond et al. (2012), o acesso ao pasto é um fator importante que contribui com o bem-estar e comportamento de bovinos leiteiros.

\section{Comportamento de bezerros}

É pelos padrões comportamentais que os animais tentam adaptar-se à influência dos agentes estressores, alternativa para melhoria das condições de bem-estar (Almeida et al., 2013). Alguns indivíduos conseguem lançar mão de diversos mecanismos de adaptação para superar os problemas, existem ainda os que conseguem enfrentar as dificuldades com êxito, indício do controle da estabilidade mental e corporal (Broom \& Molento, 2004).

A quebra do vínculo materno-filial após o nascimento altera o estado emocional dos bezerros de forma negativa e quando esses animais são criados individualmente sua capacidade cognitiva também é afetada de forma negativa, diferente do que ocorre com os animais quando criados em um ambiente enriquecido (com acesso à genitora, bezerros e grupos de vacas) demonstram melhores desempenhos em tarefa de aprendizagem (Daros et al., 2014). A mamada cruzada é um comportamento comum em bezerros alojados de forma coletiva. Estudos mostram que tal comportamento antes e durante o desaleitamento pode ser reflexo do método de desaleitamento, bem como da quantidade de leite ingerida ou da energia, também é observado em bezerros que recebem leite ad libitum via bico, mas com menor 
intensidade. Algumas evidências sugerem que o papel do receptor da mamada pode ser importante para a persistência de tal comportamento.

Os bezerros são animais pré-ruminantes (Prado et al., 1989) e sua criação tem como objetivo tornálos ruminantes funcionais (Chaves et al., 2009). O acesso ao pasto nas primeiras semanas de vida implica no comportamento de pastejo, contribuindo assim para o desenvolvimento do rúmen-retículo dessa categoria (Oliveira et al., 2007). Esses animais utilizam maior parte do tempo forrageando, sendo que durante a madrugada essa atividade é reduzida, concentrando-se os comportamentos de ruminação e ócio na medida em que o animal vai evoluindo de pré-ruminante para ruminante (Zanine et al., 2007).

Os alojamentos individuais impossibilitam a expressão dos comportamentos naturais dos bezerros, com exceção de deitar-se, levantar-se e locomover-se (Pedreira \& Primavesi, 2011). Todavia, estes animais estão em fase de desenvolvimento e necessitam de espaço físico para exercitar seus membros locomotores. Quando o sistema de criação dispõe de espaço limitado, os animais apresentam comportamento de movimento locomotor-rotacional, substituindo ocasionalmente esse comportamento por coices ou pulos (Façanha et al., 2011). O comportamento de deitar é natural da espécie. No entanto, existem alguns fatores responsáveis pelo tempo de permanência nessa posição, sendo eles o conforto que a área oferece os fatores climáticos, tipo de instalação, dentre outros. Ainda existe uma forte correlação entre o comportamento de deitar com o comportamento de ruminar (Degasperi et al., 2003). No verão, o comportamento de busca por ambientes mais sombreados torna-se mais evidenciados e quando ocorre o aumento da sensação térmica de calor, desencadeia um aumento da ingestão de água a fim de manter o organismo em homeostase térmica (Leme et al., 2005; Signoretti et al., 2013).

No pré-desmame a adoção das boas práticas de manejo, juntamente com a interação humano-animal por estímulos táteis, possuem efeitos benéficos no comportamento à longo prazo, melhorando o temperamento dos animais desmamados, bem como resposta imune e redução de respostas aversivas (medo) dos bezerro aos humanos (Silva et al., 2017).

\section{Sistema de criação de bezerras leiteiras}

Considerando as diferentes áreas geográficas e climáticas existentes no Brasil, é laborioso determinar um modelo ideal de bezerreiro padrão, pois se deve considerar as especificidades e particularidades de cada região e sistema de criação. Para a escolha do tipo de bezerreiro devem-se considerar os principais fatores de riscos (temperatura, radiação solar, umidade, ventilação e superlotação das instalações) para que a taxa de Doença Respiratória Bovina (DRB) esteja dentro do limite aceitável, ou seja, inferior a $10 \%$. As instalações precisam proteger os bezerros contra os ventos fortes e alta umidade deve garantir conforto permitindo que o animal expresse todo seu potencial genético, condições de higiene, saúde e manejar as bezerras e diminuir as ações diretas dos fatores ambientais (Miranda et al., 2003; Oliveira \& Azevedo, 2005). Segundo Façanha et al. (2011), os bezerros são animais em fase de desenvolvimento e necessitam de espaço físico para exercitar-se trabalhando de forma adequada seu aparelho locomotor evitando assim problemas futuros de articulações. Quando os estímulos naturais proporcionados pelo ambiente são restritos, favorecem o surgimento das estereotipias e prejudicam o desenvolvimento físico e produtivo dos animais (Broom \& Molento, 2004). Bezerros são animais fisiologicamente préruminantes, sua criação tem como objetivo torná-los ruminantes funcionais a um custo compatível sem prejudicar suas funções vitais nem seu desempenho futuro, economizando leite em relação ao método de criação natural (Chaves et al., 2009).

Existem alguns fatores estressantes presentes na vida dos bezerros, como o nascimento, transporte, desmame, descorna e agrupamentos. Esses fatores têm provocado grandes riscos para o animal, enfraquecendo as defesas imunológicas naturais e predispondo às doenças e infecções (Silva et al., 2001). Ao nascer, a cria permanece com a genitora de 12 a 24 horas, neste período deve-se assegurar a ingestão de pelo menos dois litros de colostro nas primeiras três horas após o nascimento e seis litros de colostro nas primeiras 12 horas (Santos et al., 1994; Santos et al., 1988). Após a apartação, o bezerro é levado preferivelmente para uma baia (abrigo) individual. A partir do segundo dia de vida, os bezerros são alimentados com leite em baldes de tetas, recebendo seis litros de leite por dia (dividido em duas refeições) até o $35^{\circ}$ dia de vida. A partir do $36^{\circ}$ dia de vida, os bezerros são alimentados com três litros de leite uma vez ao dia até o desmame. O alimento concentrado $18 \%$ de proteína bruta (PB) e $80 \%$ de 
nutrientes digestíveis totais (NDT) deve estar à disposição dos bezerros desde a segunda semana de idade (Miranda et al., 2003; Oliveira \& Azevedo, 2005; Silva et al., 2017).

Os três primeiros meses de vida dos bezerros são os mais críticos, pois o seu sistema imunológico ainda não se encontra totalmente desenvolvido. Após o nascimento o colostro (fonte de imunoglobulinas) é a principal fonte de proteção contra os microrganismos patogênicos presentes no ambiente (Santos et al., 1988). Para os animais que não conseguem ingerir o colostro e apresentam-se debilitados nas primeiras horas de vida, recomenda-se que a vaca seja ordenhada e oferecido o colostro via sonda. Nos primeiros meses de vida os animais estão muito susceptíveis as doenças, e as que mais têm causado morte nessa fase são as diarreias infecciosas e os problemas respiratórios, em sua maioria, é decorrente das condições de criação inadequadas como instalações, manejo e deficiência alimentar. Acredita-se que alguns fatores como: manejo sanitário inadequado, excesso de umidade, concentração de amônia dentro das instalações, presença de agentes causadores de doenças tem elevado os índices de diarreia e problemas respiratórios nos três primeiros meses de vida do animal. Para evitar a ocorrência das diarreias é importante manter a higiene do ambiente (local limpo, seco), desinfecção dos utensílios utilizados e abrigar os animais de ventos fortes (Campos \& Campos, 2004; Miranda et al., 2003).

O período neonatal (até 28 dias de idade) representa $75 \%$ das perdas no primeiro ano de vida, diante disso, para evitar perdas são imprescindíveis cuidados especiais com a saúde e com o desenvolvimento das futuras matrizes. Os bezerros são animais que passam por adaptações rápidas, a princípio perdem a proteção de suas mães e são expostos a um meio adverso, tornando-os sujeitos das intempéries, dos microrganismos, das diferentes condições alimentares e manejo. Na criação de bezerras os fatores de produção são de extrema importância desde os cuidados com as vacas antes do parto, do fornecimento do colostro, do corte e cura do umbigo e até aplicações de medicamentos caso necessário, mas quase sempre é uma fase deixada em segundo plano, por não apresentar um retorno econômico de forma direta. Mas, quando se dispõe de um manejo nutricional, sanitário e ambiental apropriado, a produção de bezerras é viabilizada de forma eficiente, minimizando mortalidade e maximizando a lucratividade pela retenção das bezerras fêmeas para serem as futuras matrizes do rebanho e a comercialização dos bezerros machos (Oliveira \& Azevedo, 2005; Signoretti et al., 2013).

\section{Sistema de aleitamento de bezerras}

No sistema de aleitamento natural, os bezerros permanecem com suas mães durante toda lactação, sendo desaleitados com 6-8 meses de idade. O aleitamento natural diminui a ocorrência de distúrbios gastrointestinais, pelo fato do bezerro obter o leite diretamente no teto, reduz mão-de-obra e utilização de utensílios. Essa técnica é utilizada em rebanhos leiteiros com baixo nível de tecnificação, com pouca especialização e baixa perspectiva de produção, ou ainda em rebanhos compostos de animais zebuínos que só liberam o leite na presença da cria. Quando utilizado o aleitamento natural no sistema semiextensivo, os animais são desaleitados aos oito meses de idade, já no aleitamento artificial adotado por alguns produtores, o desaleitamento ocorre de 2-3 meses de idade. A ordenha é realizada de forma mais higiênica e mais rápida. A utilização do sucedâneo no aleitamento artificial ainda não é tão expressiva, mas tende ao crescimento buscando diminuir custos com animais que apresentam como fonte principal de alimentação a dieta liquida. Para que ocorra o desaleitamento o mais importante é que o bezerro esteja consumindo no mínimo $800 \mathrm{~g}$ de concentrado/dia (Assis et al., 2005; Miranda et al., 2003; Oliveira \& Azevedo, 2005).

\section{Sistema de criação de bezerros a pasto}

Nesse sistema de criação os bezerros podem ser criados a pasto desde o nascimento, essa alternativa de criação minimiza custos com mão-de-obra e instalações. Nos piquetes é disponibilizado uma cobertura com cocho para o alimento concentrado e volumoso, fornecendo o volumoso em cocho apenas na época de menor crescimento do pasto (Figura 1). Os piquetes não devem ser localizados em áreas úmidas evitando a proliferação de microrganismos patogênicos, devendo possuir uma pequena declividade possibilitando a drenagem do terreno, disponibilidade de bebedouros com água fresca e limpa. Na época das chuvas, na parte coberta pode-se utilizar areia, cascalho, cama (palhas, cascas de arroz, cepilho de madeira), para amenizar a umidade presente no ambiente em que os animais estão dispostos. Esse sistema é indicado para rebanhos que contém poucos animais, pois quando se coloca um 
grande número de animais em um local pequeno, corre-se o risco de disseminação de doenças, dificultando o manejo e o controle sanitário. É necessária a instalação de uma baia enfermaria dentro do curral para que os animais que apresentarem algum problema passem por tratamentos e logo após retornem aos seus piquetes. Desta forma, evita-se a disseminação de doenças (Campos \& Campos, 2004).

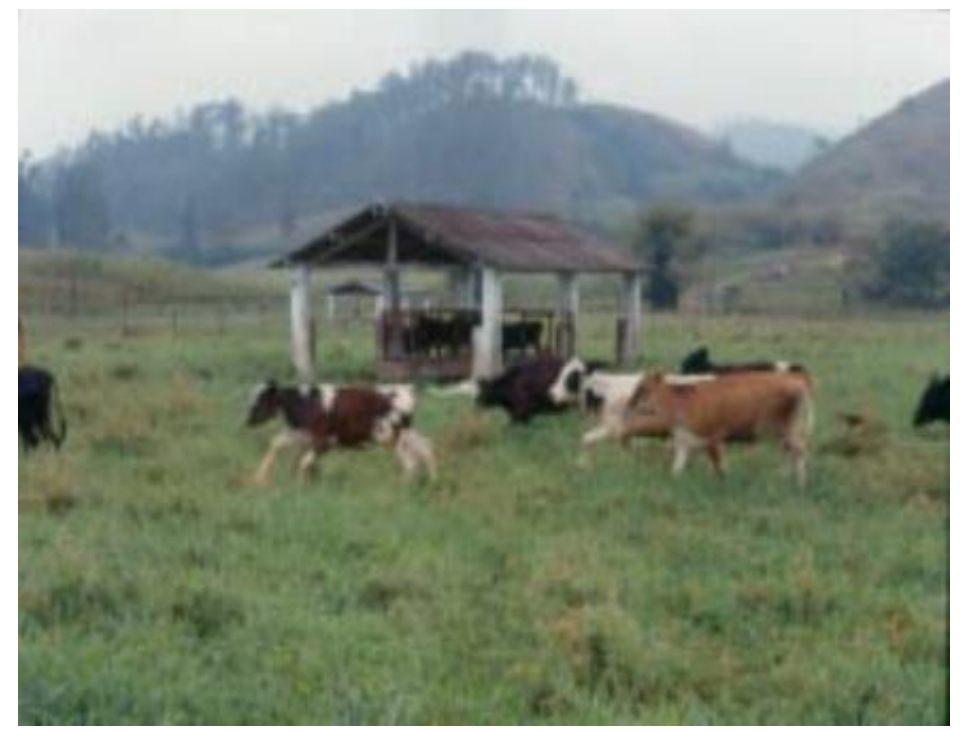

Figura 1. Bezerros criados a pasto. Fonte: Circular Técnica EMBRAPA

\section{Sistema de abrigo individual "Casinhas Tropicais"}

No Brasil, grande parte da criação de bezerras é realizada em sistema de abrigos individuais, conhecidos como "casinhas tropicais" alternativas para a fase de aleitamento. Este é o manejo mais adequado para evitar a proliferação de doenças em bezerros recém-nascidos, nos primeiros dois meses após o parto. Os animais permanecem do $1^{\circ}$ dia de vida ao $60^{\circ}$ dia ou até mesmo $90^{\circ}$ dia (o tempo varia de acordo com o manejo adotado pela fazenda), quando o consumo diário de concentrado estiver em torno de $800 \mathrm{~g} /$ dia. Algumas das vantagens desse método de criação é a fácil desinfecção e limpeza do local, proteção do animal contra chuva e o excesso de sol, os animais são melhores observados, além da mobilidade do abrigo possibilitando a quebra do ciclo de vida de microrganismos patogênicos. Todavia, o sistema de abrigo individual, impede os bezerros expressarem seu comportamento natural como brincar, correr ou até mesmo comportamento filial entre eles, pois ficam presos por uma corda com acesso restrito apenas ao pasto, ração e água em cochos individuais e não tem contato com outros animais. Algumas pesquisas mostram que é possível obter benefícios econômicos e considerar o bemestar dos bezerros, utilizando abrigos que promovam o bem-estar animal considerando seus comportamentos naturais (Campos \& Campos, 2004; Miranda et al., 2003; Oliveira \& Azevedo, 2005). Nos dois primeiros meses de vida, os bezerros devem ser criados de forma individual, as instalações devem estar próximas umas das outras e conceder aos animais a visualização dos outros animais, para que logo após o desaleitamento a socialização ocorra de forma rápida e os animais não tenham dificuldades em adaptar-se a ambientes coletivos (Campos \& Campos, 2004; Miranda et al., 2003; Oliveira \& Azevedo, 2005). Para a instalação de baias individuais fixas, deve-se considerar a área de 1,50 a $1,80 \mathrm{~m}^{2}$ por animal. Em relação às casinhas individuais à pasto, deve-se respeitar uma distância mínima de $2 \mathrm{~m}$ entre cada uma delas e fornecer uma área total de 2,2 a 3,0 $\mathrm{m}^{2}$ por animal. Para que disponham de uma melhor ventilação natural, permitindo a renovação do ar e eliminação dos gases gerados pelo acúmulo de fezes e urina dos animais (monóxido de carbono, metano, amônia, sulfeto de hidrogênio); além disso, a maior incidência dos raios solares dentro das instalações garante a redução da umidade no local. Para isso, o bezerreiro deve ser instalado numa posição onde ocorra penetração dos raios solares na parte da manhã, onde ofereça proteção contra os ventos e que os terrenos sejam bem drenados para evitar o encharcamento do solo (Campos \& Campos, 2004; Miranda et al., 2003; Oliveira \& Azevedo, 2005). Muitos produtores já utilizam os abrigos ou casinhas com sucesso, as quais são planejadas para as regiões de clima temperado e frio, mas existem alguns relatos de produtores que os animais ficam a maior parte de seu tempo fora dos abrigos mesmo nos horários mais quentes ou durante 
as chuvas (Campos \& Campos, 2004). O uso de abrigos individuais tem aumentado devido aos bons resultados, pois proporciona menor problema sanitário, menor mortalidade e promovem um desejável aumento no consumo de concentrados e volumosos.

Campos et al. (2005) analisaram o ambiente térmico no interior de diferentes tipos de abrigos individuais para bezerros, no período de primavera/verão e outono/inverno. Verificaram que nas regiões onde as condições de verão são consideradas severas (temperatura média de $31^{\circ} \mathrm{C}$ ), torna-se inviável o uso de sombrite como alternativa de sombreamento para os animais, uma vez que o valor encontrado para Índice de Temperatura do Globo e Umidade (ITGU) foi de 87,44 o qual supera consideravelmente o limite de 84,00. Segundo os mesmos autores recomenda-se a utilização do abrigo individual (bezerreiro aberto ou fechado nas laterais) modelo "Casinha Tropical", onde os valores de ITGU (84,0 e 84,5) foram muito próximos ao limite. Segundo Almeida et al. (2010) o ITGU é preciso nas medições de conforto térmico dos ruminantes, ele engloba os efeitos da temperatura de bulbo seco, velocidade do ar, umidade e da radiação solar direta e indireta.

Diversos são os materiais utilizados na confecção dos abrigos individuais e diversas são as versões apresentadas, a exemplo, a casinha individual (Figuras 2 a 7). Os abrigos podem ser construídos por madeira, aglomerados, bambu, lona, telhas e amianto, sapé, metal ou fibra de vidro. O abrigo individual vem sendo muito utilizado nos sistemas mais intensificados e especializados com melhores padrões técnicos e produtividade elevada. Quando os animais são desaleitados, os abrigos são limpos, desinfetado e alocado em outro lugar para ser ocupado posteriormente por um bezerro recém-nascido (Campos \& Campos, 2004; Oliveira \& Azevedo, 2005).

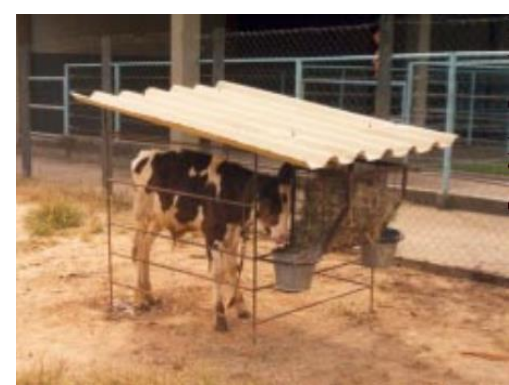

Figura 2. Abrigo individual de estrutura metálica. Fonte: Cristiano Barros de Melo

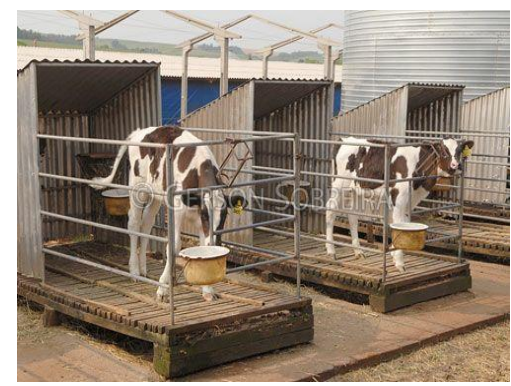

Figura 5. Bezerreiro individual com estrado de madeira. Fonte: Gerson Sobreira

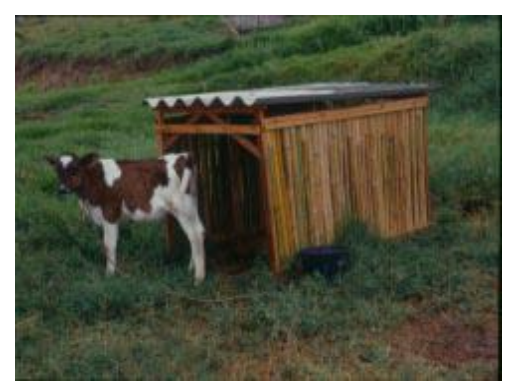

Figura 3. Abrigo individual de madeira. Fonte: Circular Técnica EMBRAPA

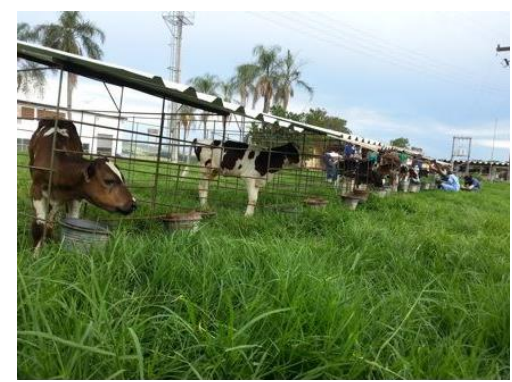

Figura 6. Bezerreiro sistema de alojamento à pasto. Fonte: Viviane Gomes

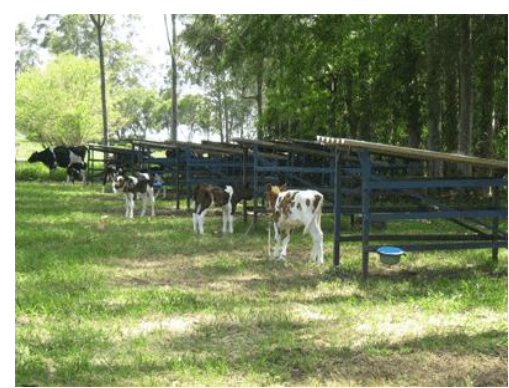

Figura 4. Bezerreiros individuais. Fonte: Carla Maris Machado Bittar

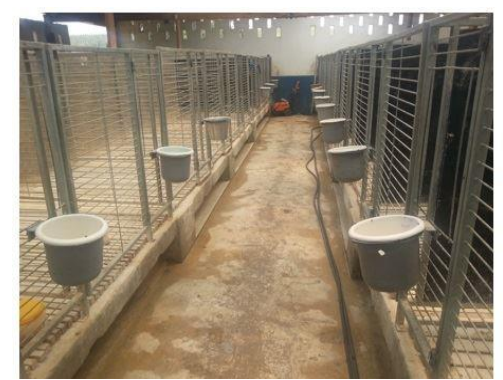

Figura 7. Baias individuais de alvenaria em galpão. Fonte: Viviane Gomes

Os bezerreiros mais comuns existentes em nosso país requerem maiores investimentos, sendo eles bezerreiros de alvenaria ou de madeira. Para a mantença do bezerreiro seco e limpo exige muita mãode-obra, principalmente quando existe a necessidade de remoção dos animais, da cama, do estrado para a desinfecção do ambiente e posteriormente realocação dos animais em suas respectivas instalações (Campos \& Campos, 2004).

\section{Sistema de criação com uso de sombrite}

Campos \& Campos (2004) verificaram que é possível a utilização de sombrite na criação de bezerras (Figuras 8 e 9), pois proporciona aos animais desenvolvimento semelhante dos animais criados em abrigos individuais. Desta forma, a escolha de um sistema de criação depende dos custos e do número 
de animais a ser alojado, já que o desenvolvimento dos animais é semelhante aos sistemas já mencionados. Segundo Oliveira \& Azevedo (2005) alojamentos individuais uns próximos dos outros possibilitam melhor adaptação de bezerras ao serem inseridas em ambientes coletivos ("free stall", semi confinamento, piquetes).

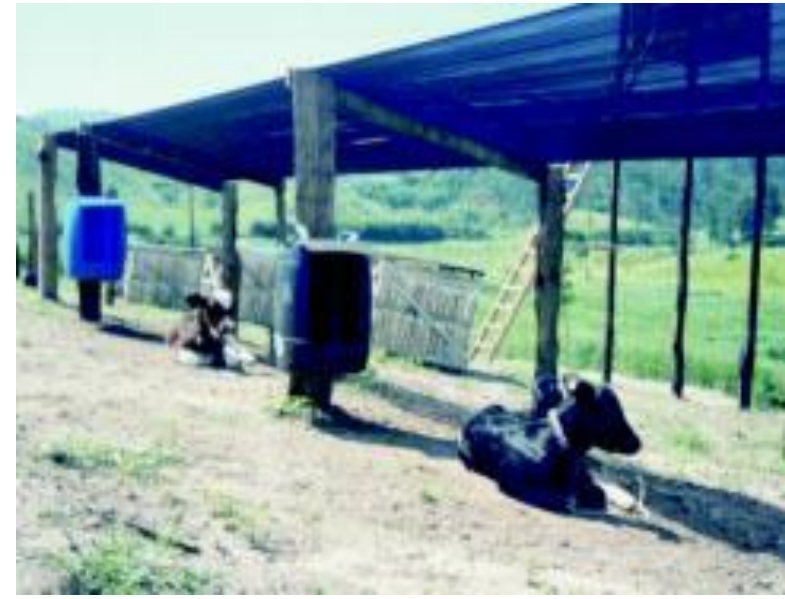

Figura 8. Bezerro sob sombrite. Fonte: Circular Técnica EMBRAPA

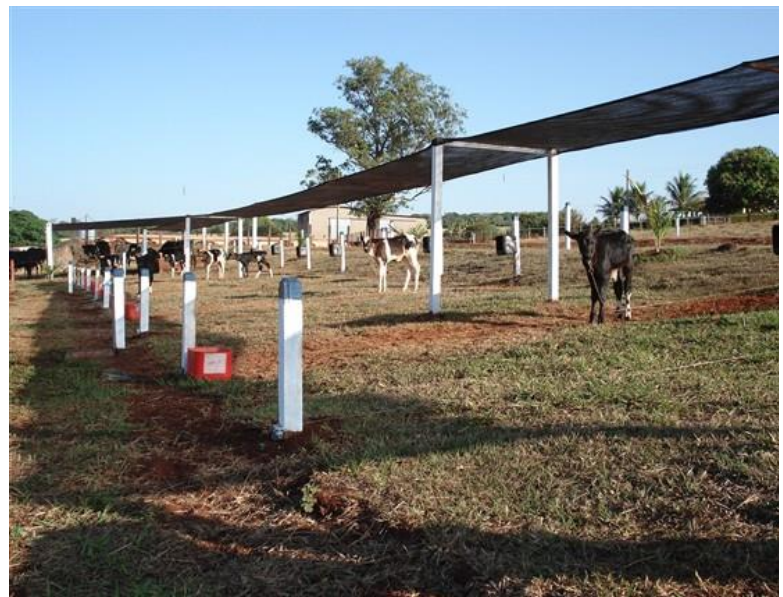

Figura 9. Bezerreiros modelo argentino. Fonte: Bruno V. Nadruz

Animais criados em grupo (Figura 10) são mais ativos favorecendo comportamentos desejáveis e elevando índices de produtividade o que é vantagem para os produtores. Campos et al. (2005) analisaram a criação de bezerros com a utilização de sombrite (malha de $50 \%$ de sombra e aberto em todas as laterais) nas condições de temperatura média de $23,1^{\circ} \mathrm{C}$ (outono/inverno). Verificaram que o resultado obtido de ITGU para esse sistema foi de 74,92, encontrando-se próximo à faixa tida como de conforto $(74,0)$. Esse sistema tem como finalidade substituir outros sistemas de criação, pois constitui uma opção mais econômica e de fácil instalação.

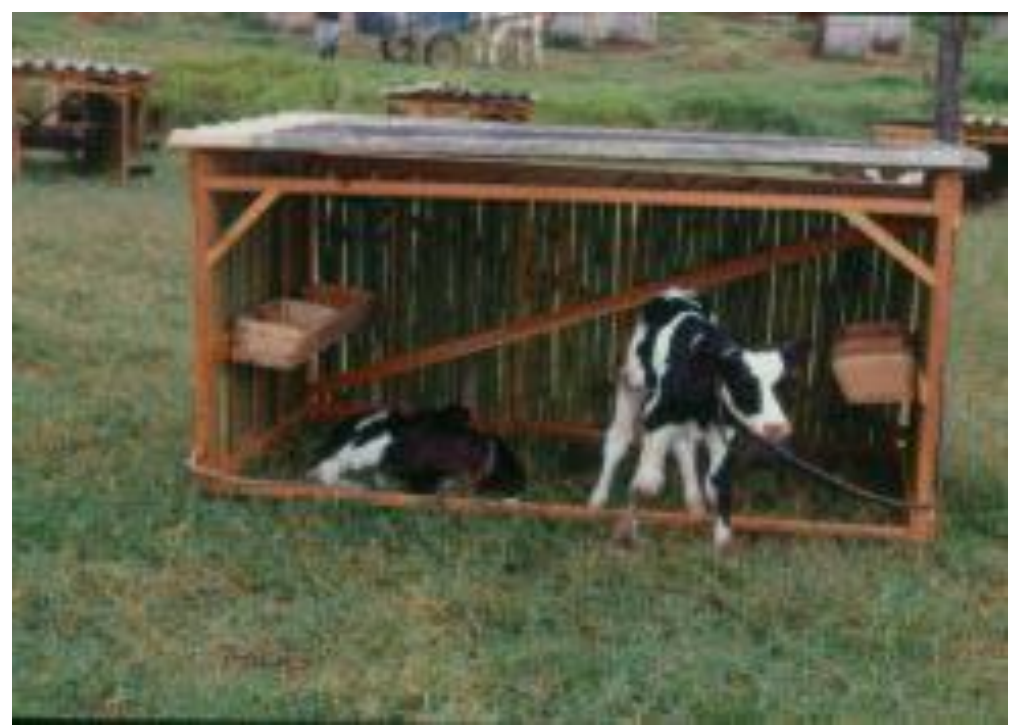

Figura 10. Abrigo duplo fechado. Fonte: Circular Técnica EMBRAPA

\section{Sistema de criação em grupos}

Segundo Pedreira \& Primavesi (2011) crescentes preocupações com bem-estar, tem aumentado o número de pesquisas, as quais têm oferecido alternativas e opções mais humanitária de alojamento. Uma opção é alojar bezerras em pares ou também podem ser alojadas em pequenos grupos. Todavia, os grupos devem ser estáveis, com no máximo sete ou oito bezerras com idades semelhantes. Grupos maiores são mais susceptíveis a doenças. Os sistemas de pares e de pequenos grupos de alojamentos são opções viáveis, quando se tem habilidade e é oferecida atenção devida para essa categoria animal. O 
manejo nesse sistema de criação exige um ambiente limpo, qualidade de colostro e observações frequentes dos animais.

O sistema de abrigo duplo (Figura 10) torna-se mais econômico, pois reduz a demanda por abrigos, permite interação social entre animais e o estímulo para o aprendizado dos animais jovens com os mais velhos, induzindo também o consumo precoce de concentrado (Campos \& Campos, 2004). Segundo Pedreira \& Primavesi (2011) a socialização pode incentivar a ingestão de alimentos sólidos precocemente (bezerras observando suas parceiras começarão a ingerir o mesmo alimento precocemente), permitindo uma transição mais suave dos animais alojados em grupos.

Delfino et al. (2012) afirmam ser aconselhável que a partir da $6^{\mathrm{a}}$ ou $7^{\mathrm{a}}$ semanas até oito meses de idade, os bezerros sejam alocados em baias coletivas, sendo necessária uma área de 2,0 a 2,5 m²/animal. Criar as bezerras em instalações individuais na fase de aleitamento é a forma mais adequada, pois reduz o risco de disseminação de doenças por contato direto entre os animais. Além disso, permite um melhor controle da quantidade de alimento ingerido por animal, facilita a ingestão do alimento e evita problemas de dominância entre animais. Mas, por outro lado, atualmente preocupações com bem-estar dos animais tem sugerido o agrupamento de bezerras em pequenos lotes para que ocorra socialização entre os animais reduzindo assim o estresse. O problema desse tipo de criação é que há uma maior chance da ocorrência de contaminações cruzadas por contado direto e variações no ganho de peso. Em propriedades que adotam o sistema de bezerreiro coletivo e os animais alimentam-se através de alimentadores automáticos, recomenda-se o agrupamento de no máximo até 25 bezerras por lote, respeitando o espaço de 2,3 a $2,8 \mathrm{~m}^{2} /$ animal.

O'Driscoll et al. (2006) avaliaram o consumo de leite e alimentação de bezerros alojados em currais individuais e comportamentos competitivos, alimentação e consumo de leite quando os animais focais foram inseridos em pequenos grupos, verificaram um declínio de $20 \%$ no consumo quando os bezerros tiveram contato com outros, houve também uma semelhança no comportamento e ingestão de alimento dois dias antes de serem alojados em grupos e três dias após o contato com outros animais, eles foram capazes de restabelecer seus padrões alimentares 24 horas depois de inseridos nos grupos, ocorrendo apenas efeitos transitórios sobre o comportamento alimentar, sendo necessários mais estudos para avaliação de animais mantidos em grupos maiores.

\section{Considerações finais}

$\mathrm{Na}$ bovinocultura de leite a interação do ser humano com os animais tem um aspecto importante e relevante a ser considerado em sistemas de produção animal. Durante todas as fazes de vida de um animal ocorre a interação humano-animal. Indo desde os cuidados antes do parto, pós-parto, até o descarte desse animal. Nos primeiros dias de vida, é realizado todo manejo necessário para garantir boa sanidade e o bem-estar dos bezerros. O sistema de criação adotado deve proporcionar aos animais um ambiente rico e que permita a expressão de seus comportamentos naturais, contribuindo para um grau de bem-estar bom dos animais. Também, um planejamento nutricional e sanitário adequado, juntamente com a genética e o ambiente, quando esses pilares são atendidos, consequentemente aumentam-se os índices produtivos e maximiza-se um retorno econômico nas propriedades.

\section{Referências bibliográficas}

Almeida, G. L. P., Pandorfi, H., Barbosa, S. B. P., Pereira, D. F., Guiselini, C. \& Almeida, G. A. P. (2013). Comportamento, produção e qualidade do leite de vacas Holandês-Gir com climatização no curral. Revista Brasileira de Engenharia Agrícola e Ambiental, 17(8), 892-899. doi: https://doi.org/10.1590/S1415-43662013000800014.

Almeida, P. A., Oliveira, J. R. \& Mantovani, M. M. (2010). Determinantes da interação homem-animal. PUBVET, 4(4), 144.

Assis, A. G., Stock, L. A., Campos, O. F., Gomes, A. T., Zoccal, R. \& Silva, M. R. (2005). Sistemas de produção de leite no Brasil. Embrapa Gado de Leite-Circular Técnica, 1, 1-6.

Bond, G., B., Almeida, R., Ostrensky, A. \& Molento, C. F. M. (2012). Métodos e pontos críticos de bem-estar de bovinos leiteiros. Ciência Rural, 42, 1286-1293. doi: https://doi.org/10.1590/S010384782012005000044 . 
Broom, D. M. (1986). Indicators of poor welfare. British Veterinary Journal, 142(6), 524-526.

Broom, D. M. \& Molento, C. F. M. (2004). Animal welfare: concept and related issues-review. Archives of Veterinary Science, 9(2), 1-11.

Campos, A. T., Klosowski, E. S., Gasparino, E., Campos, A. T. \& Santos, W. B. R. (2005). Análise térmica de abrigos individuais móveis e sombrite para bezerros. Acta Scientiarum. Animal Sciences, 27(1), 153-161.

Campos, O. F. \& Campos, A. s. T. (2004). Instalações para bezerros de rebanhos leiteiros. Embrapa Gado de Leite-Circular Técnica, 1, 1-6.

Chaves, A. S., Oliveira, R. C., Junior, G. P., Viana, A. d. A. C., Melo, L. Q., Costa, S. F. \& Pereira, M. N. (2009). Desempenho de bezerros alimentados com concentrado extrusado ou farelado. Ciência Animal Brasileira, 1, 826-829.

Daros, R. R., Costa, J. H. C., von Keyserlingk, M. A. G., Hötzel, M. J. \& Weary, D. M. (2014). Separation from the dam causes negative judgement bias in dairy calves. PLoS One, 9(5), e98429.

Degasperi, S. A. R., Coimbra, C. H. \& Pimpão, C. T. (2003). Estudo do comportamento do gado Holandês em sistema de semi-confinamento. Revista Acadêmica: Ciência Animal, 1(4), 41-47.

Delfino, L. J. B., Souza, B. B., Silva, R. M. N. \& Silva, W. W. (2012). Influência bioclimatológica sobre os parâmetros hematológicos de bovinos leiteiros. Agropecuária Científica no Semiárido, 8(2), 815. doi: http://150.165.111.246/ojs-patos/index.php/ACSA/article/view/171.

Façanha, D. A. E., Vasconselos, Â. M., Chaves, D. F., Silva, W. S. T., Morais, J. H. G. \& Olivo, C. J. (2011). Respostas comportamentais e fisiológicas de bezerros leiteiros criados em diferentes tipos de instalações e dietas líquidas. Acta Veterinaria Brasilica, 5(3), 250-257.

Gibbs, E. P. J. (2014). The evolution of One Health: a decade of progress and challenges for the future. Veterinary Record, 174(4), 85-91.

Leme, T., Pires, M., Verneque, R. d. S., Alvim, M. J. \& Aroeira, L. J. M. (2005). Comportamento de vacas mestiças Holandês x Zebu, em pastagem de Brachiaria decumbens em sistema silvipastoril. Ciência e Agrotecnologia, 29(3), 668-675.

Martins, M. F. \& Pieruzzi, P. A. P. (2011). Bem estar animal na bovinocultura leiteira. In M. V. D. Santos, L. F. P. Silva, F. P. Rennó \& R. D. Albuquerque (Eds.), Novos desafios da pesquisa em nutrição e produção animal. Itirapina, São Paulo, Brasil: VTN.

Miranda, J. E. C., Ribeiro, A.C., Campos, O. F. \& Novaes, L. P. (2003). Cria e recria de fêmeas leiteiras: passo a passo. Embrapa Gado de Leite-Comunicado Técnico, 1, 1-6.

O’Driscoll, K., Von Keyserlingk, M. A. G. \& Weary, D. M. (2006). Effects of mixing on drinking and competitive behavior of dairy calves. Journal of Dairy Science, 89(1), 229-233.

Oliveira, A.A. \& Azevedo, H. C. (2005). Criação de bezerras em sistemas de produção de Leite. Embrapa Tabuleiros Costeiros. Circular Técnica, 1-6.

Oliveira, J. S., Zanine, A. M. \& Santos, E. M. (2007). Fisiologia, manejo e alimentação de bezerros de corte. Arquivos de Ciências Veterinárias e Zoologia da UNIPAR, 10(1), 39-48.

Pedreira, M. S. \& Primavesi, O. (2011). Aspectos ambientais na bovinocultura. In T. T. Berchielli, A. V. Pires \& S. G. Oliveira (Eds.), Nutrição de Ruminantes (Vol. 1, pp. 521-536). Jaboticabal, Brazil: FUNEP.

Prado, I. N., Toullec, R., Guilloteau, P. \& Guguen, J. (1989). Digestion de protèines de pois et de soja chez le veau preruminant. II. Digestibilité apparente à la fin d'ileon et du tube digestif. Reproduction Nutrition Development, 29, 425-439.

Santos, G. T., Bertolini, D. A., Macedo, F. A. F., Prado, I. N. \& Martins, E. N. (1994). Variabilidade em imunoglobulina $\mathrm{G}(\mathrm{IgG})$ no colostro de cabra de primeira ordenha e absorção intestinal de $\operatorname{IgG}$ pelos cabritos recém-nascidos. Brazilian Archives of Biology and Technology, 37(2), 285-292.

Santos, G. T., Grongnet, J. F., Prado, I. N. \& Lareynie, J. (1988). Efeito da ordem de lactação sobre os níveis em imunoglobulinas $\mathrm{G}$ (IgG) do colostro bovino. Revista UNIMAR, 10(1), 31-38. 
Signoretti, R. D., Veríssimo, C. J., Dib, V., Souza, F. H. M., Garcia, T. S. \& Oliveira, E. M. (2013). Desempenho e aspectos sanitários de bezerras leiteiras que receberam dieta com ou sem medicamentos homeopáticos. Arquivos do Instituto Biológico, 80(4), 387-392.

Silva, L. A. F., Fioravanti, M. C. S., Dias Filho, F. C. \& Eurides, D. (2001). Sanidade dos bezerros leiteiros da concepção ao desmame. Goiânia: Talento, 1, 1-87.

Silva, L. P., Sant'Anna, A. C., Silva, L. C. M. \& Paranhos Costa, M. J. R. (2017). Long-term effects of good handling practices during the pre-weaning period of crossbred dairy heifer calves. Tropical Animal Health and Production, 49(1), 153-162.

Zanine, A. M., Santos, E. M., Parente, H. N., Ferreira, D. J. \& Cecon, P. R. (2007). Hábito de pastejo de vacas lactantes Holandês x Zebu em pastagens de Brachiaria brizantha e Brachiaria decumbens. Arquivo Brasileiro de Medicina Veterinária e Zootecnia, 59(1), 175-181.

Recebido: 7 outubro, 2018.

Aprovado: 1 novembro, 2018.

Publicado: 23 janeiro, 2019.

Licenciamento: Este artigo é publicado na modalidade Acesso Aberto sob a licença Creative Commons Atribuição 4.0 (CC-BY 4.0), a qual permite uso irrestrito, distribuição, reprodução em qualquer meio, desde que o autor e a fonte sejam devidamente creditados. 